\title{
LANGUAGE BARRIERS TO LEARNING SCIENCE
}

Elaine Ridge, Faan Jordaan and NC Nangu

This article draws on a study done in 1996 by Jordaan and Mangu which sought to determine how well pupils understand concepts which appear frequently in their textbooks and also to establish whether support material would facilitate learning. This article is not as much interested in the performance level of the students as the underlying reasons for the poor performance. The article explores some of the responses made by students in order to define their difficulties more precisely and concludes by making recommendations for learning and teaching.

Hierdie artikel bou voort op 'n studie wat in 1996 deur Jordaan en Mangu gedoen is wat probeer het om te bepaal hoe goed leerders konsepte wat gereeld in hulle handboeke voorkom, verstaan en ook om vas te stel of ondersteunende materiaal die leerproses fasiliteer. Hierdie artikel is nie soseer gerig op die prestasievlakke van die leerders nie, maar eerder op die onderliggende redes vir hulle swak prestasie. Die artikel ondersoek sekere van die response van die leerders en poog daardeur om van die struikelblokke wat wetenskaplike diskoers aan die leerders bied meer presies te omskryf. Die artikel sluit af met voorstelle vir verbeterings aan die leerproses en aan onderriglewering.

\section{INTRODUCTION}

Black students at secondary level in South Africa generally had limited success in subjects like science. Clearly, the explanation does not lie in cognitive deficiency. Part of the explanation clearly lies in the use of English as the language of teaching (LOLT). However, the precise nature of the difficulty it presents at secondary level has not been closely defined. This paper attempts to define more clearly some possible barriers which the use of English as LOLT could constitute, drawing primarily on a recent study done by Jordaan and Nangu (1996).

Their study arose from the researchers' observation that students at the school at which one of them had been teaching had limited competence in English even at Grade 10 level. Studies like the one done by Cassels and Johnstone (1983) have shown that difficulties in science can not be laid at the door of LOLT alone. Interpreted in the light of Cummins (1983), the limited cognitive academic language proficiency (CALP) skills of the students could be said to have been the result of a transition from isiXhosa as LOLT to English as LOLT being made before they had acquired a sufficient level of language proficiency to make academic learning possible. 
As a first step, Jordaan and Nangu (1996) identified a list of the words/concepts which form part of common use in scientific discourse, and they set out to determine the extent to which these words/concepts were not understood or even misunderstood by students. Their rationale was that if they could show that the students did not understand these concepts, it would provide evidence that their lack of success could be ascribed in part to language. In order to arrive at a more nuanced answer, an attempt was also made to determine whether texts written in plainer English, as well as summaries of key content in isiXhosa, could make learning more successful.

In this pilot project, 133 grade 8 pupils (divided into 3 classes: A, B and C) at a school in the Western Cape were involved. The classes were heterogeneous groups that had been divided randomly by the school into three groups of comparable ability. In an attempt to reduce the number of variables, all three classes were taught by the same person, with every effort being made to use the same overall pattern of teaching.

The topic chosen was Elements and Compounds, arguably a central aspect in the General Science curriculum.

In what follows, three parts of the study will first be discussed: the vocabulary questionnaires, the plain English text and the summary of key concepts in isiXhosa and the test of key concepts in elements and compounds. In each case, the findings of the study will be used to illustrate some of the difficulties students experience.

\section{ANALYSIS OF ASPECTS OF THE STUDY}

\subsection{The Vocabulary Questionnaire}

Two questionnaires were compiled in the following way. First, a number of std 6 science textbooks were used to identify words commonly or frequently used in the English text that could prove problematic. These words were given to Afrikaans-speaking pupils from another local school to test the intuition of the researchers and at the same time to gather data which could be used to construct distractors for multiple-choice questions. The resultant multiple choice questions were supplemented by questions drawn from an extensive study conducted in Scotland by Cassels and Johnstone (1985).

\subsubsection{Types of questionaires}

Four types of questions were used in the questionnaires:

Type A consisted of items in which the students were required to select a word from four given options to fill the gap in a sentence, e.g.:

Choose one of the following $(A, B, C, D)$ to complete the sentence below correctly.

While he was doing the experiment, a black substance suddenly (......) in the test tube.

A generated

B appeared

C arranged

D contained 
Type B consisted of items in which a word was given in the context of a sentence or a phrase and students were required to select its correct meaning from four given options, e.g.:

If a flame continues burning, it means the flame

A changes its colour

B keeps on burning

C disappears after a while

D starts burning

Type $\mathrm{C}$ consisted of items in which pupils were given a word and were required to determine in which one of the four sentences the word is used correctly, e.g.:

In which sentence is the word composed used correctly?

A The boy put composed in his garden to let the plants grow better.

B Air is composed of different gases.

C He composed the rocks according to their age.

D She composed of all the chemicals she no longer used.

Type D consisted of items in which a word was given on its own and students were required to select a synonym for an uncontextualised word, e.g.:

\section{Constituent means}

$\begin{array}{ll}\text { A } & \text { mixture } \\ \text { B } & \text { all } \\ \text { C } & \text { compared } \\ \text { D } & \text { part }\end{array}$

These questions were further distinguished as having an everyday context (see example provided under Type B), a scientific context (see example provided under Type A), both an everyday context and a scientific context (see example provided under Type C) and no context (see example provided under Type D).

The reason for using different structures was to determine whether the structure of the question had an influence on the performance levels of the pupils. However, since the difference between the scores for the different types of questions was not significant, no firm conclusions could be drawn on the effect of the structure of the questions. It is, perhaps, worth noting that the questions which required the students to fill the gaps (Type A) were answered least well. More research would, of course, be necessary before any confident conclusions could be drawn on possible reasons for this.

It is interesting to note, however, that the pattern was not the same in Questionnaire B. Since, however, only six items (two in Questionnaire A and 4 in Questionnaire B) were involved and the differences between the scores for the different types of questions is not great, firm conclusions cannot be drawn. 


\subsubsection{Some insights provided by the data}

The overall performance on the vocabulary question, in terms of scores obtained, was dismal, as the following statistics show:

The averages of the correct responses for Questionnaire A and B were $28,8 \%$ and $27,2 \%$ respectively

Only $4(5.6 \%)$ of the 72 items were correctly answered by more than $50 \%$ of the pupils Only $12(16.7 \%)$ of the 72 words were correctly answered by more than $40 \%$ of the students

Fewer than $20 \%$ of the pupils answered $18(25 \%)$ of the 72 items correctly.

Overall performance is clearly a cause for concern. However, the discussion in this paper will focus on the insights the data provides on the ways in which language acts as a hindrance to students rather than on the students' level of performance. The aspects selected for discussion in this paper are the role of language in testing and confusion of words as a result of the inability to recognise particular written or aural distinctions.

In the discussion, the percentage of pupils who selected an option will be given in brackets immediately to the left of the option.

\subsubsection{Language of the questions}

The wording of multiple choice questions can obscure the question. An exploration of the finding with respect to one of the items in Questionnaire A seems to provide evidence of this:

If a flame continues burning, it means the flame

$(43,3 \%) \quad$ changes its colour

$(31,7 \%) \quad$ keeps on burning

$(10,0 \%)$ disappears after a while

$(13,3 \%) \quad$ starts burning

$(1,7 \%) \quad$ no response

Seen as a reflection of the knowledge of the students, this finding cannot be interpreted with confidence and may serve to highlight the importance of eliciting explanations from learners as to their reasons for making certain choices. Without corroboration, the reasons given by researchers for the choices made by pupils, however plausible, remain speculative. While in the case of those who selected option D (starts burning), one may conclude that the students did not understand the concept, an equally firm conclusion cannot be drawn in the case of those who selected option A. It may well be argued that the introductory sentence would have to read: If a flame continues burning, it will mean that the flame (changes colour), for this option to be 'correct'. In other words, it would then be a statement of cause and effect. It is true: for the flame to change colour, it would have to continue burning. In the context of scientific explanation, therefore, it can be argued that students who apply their knowledge of observed scientific laws are demonstrating an understanding of science. The problem here is not conceptual understanding, but a failure to detect a subtle linguistic difference signalling a different meaning. 
A similar argument can be based on the answers given to the following item:

During the experiment, we had to establish how much salt was present in the water. This means we had to

(21.7\%) find out how much salt was present in the water

$(55.0 \%)$ see how much salt could dissolve in the water

$(20,0 \%) \quad$ explain how much salt was present in the water

$(0 \%)$ describe how much water was present in the water

$(3,3 \%) \quad$ No response

A complication here lies in the ambiguity of the context and how much an effect it has on the students' ability to establish meaning. To see how much does have the broad sense of establishing. However, coupled with dissolved, it clearly does not constitute a correct answer. The students have probably been drawn to the more concrete situation described in the second option. It suggests an experimental procedure.

Like the previous item, the responses to this item highlight a testing problem. They point to the serious disadvantages multiple choice questions may hold for students whose level of language competence makes them more likely to fall prey to 'tricks'. It seems that they did not recognise the need to take account of the entire sentence when only one word seems to be at issue. Unfamiliarity with multiple choice techniques could prevent students from showing what they know.

Providing a specific option may be another problem. It may have had too strong an attraction. Another example where students selected the most concrete or specific option is the following item:

The components of the car are

the parts which make up the car

$(56.7 \%)$

the petrol and oil needed to run the car

the people that own the car

the people who drive the car

The students in this study were not alone in their seemingly poor understanding of components. It is interesting to observe that in the study done in Scotland, Cassels and Johnstone (1985:7) found that the Scottish children in their study confused component with compound, competent, and opponent.

It would have been interesting to see what effect there would have been on the distribution of responses had wheels, body, engine etc. been used instead of parts.

It is, perhaps, important to acknowledge that guessing may have played a part. Clearer evidence that guessing played a significant role in the answers to most questions in Jordaan and Nangu's (1996) study can be seen in the responses given to the following two items where guessing played a substantial role: 
Complex means

$(15.0 \%) \quad$ simple

(15.0\%) concentrated

$(41.7 \%) \quad$ natural

(28.3\%) complicated

When gas is generated during a chemical reaction, it means that

(28.3\%) the gas is formed during the reaction

$(21.7 \%)$ the gas causes electricity to be formed

$(25.0 \%)$ gas is dissolved in water during the reaction

$(20.0 \%) \quad$ a gas reacts with other substances in the test tube

$(5.0 \%) \quad$ No response.

The strong support for natural in the first of these items suggests uncertainty with a substantial group of students choosing a familiar word. In the second case, it is the even distribution among the four options that points to guessing rather than an informed or considered decision.

In the B questionnaire, a similar tendency was noted. In their answers to the following item, the respondents chose complete (the most familiar word). ${ }^{1}$

Choose one of the following ( $\mathrm{A}, \mathrm{B}, \mathrm{C}$ or $\mathrm{D}$ ) to complete the sentence below correctly. Certain (....) substances can be broken up into simpler substances.
$(7.5 \%)$
compiled
(13.8\%)
complex
(22.5\%)
composed
$(52.5 \%)$
complete
(3.8\%)
No response.

\subsubsection{Confusion of words}

A second way in which language affects the ability to grasp what is being communicated is confusion of words. The first cause appears to lie in inadequate aural discrimination. This may be deduced in the students' support for the following distractors in the A Questionnaire :

The boy put composed in his garden to let the plants grow better (confusion with compost);

After going on a diet the girl is much similar now (confusion with slimmer);

He is following a coarse at the university (confusion with course).

It can also be argued that pupils could see a cause and effect logic. A 'complete' substance could be broken down into its parts in the same way as a construction using blocks could be broken down. 
Children who do not listen to their parents coarse a lot of trouble (confusion with cause).

The B questionnaire revealed similar confusions. Investment and Investigation were confused, as were sample, simple, and example.

Other examples point to another set of problems arising from the inability to make fine discriminations while reading. This would explain their support for :

They always complete to see who is the best soccer player (confusion with compete).

Another way in which language may play a role in the lack of learner success can be inferred from the answers to this item:

Constituent means

$\begin{array}{ll}(36,7 \%) & \text { mixture } \\ (13,3 \%) & \text { all } \\ (30,0 \%) & \text { compared } \\ (15,0 \%) & \text { part } \\ (5,0 \%) & \text { no response }\end{array}$

The responses suggest that students have a serious misconception of constituent. $50 \%$ of the students ascribed a meaning to constituent that is, in fact, opposite in meaning to it. The cause of the misconception may be that a strong association has been formed between constituent and mixture as a result of collocations such as one of the constituents in the mixture is ....

The final group of items discussed in this section shows the ways in which words in common use, in one sense, and in scientific use, in another, could lead to confusion or to misconceptions being formed.

$(21.7 \%) \quad$ If you correspond correctly to the teacher's question, you may leave.

(16.7\%) He said he would correspond to my letter when he reached Johannesburg.

(28.3\%) The properties of both the liquids correspond to those of water.

(26.7\%) He wrote a correspond to the newspaper to tell them about the pollution in the town.

(6.7\%) No response.

It is also interesting to note the confusion between correspond and respond as well as the very strong association between correspond and letter writing which underlies the choice of the second and fourth options.

\subsection{The Simplified Text}

The Grade 8A class (37) students received the simplified version of the chapter in the textbook, a well as an extended summary in English. The Grade 8B group (52 students) used 
the normal textbook and an extended summary in English. The simplified version drew on the findings of the vocabulary questionnaire.

The F-ratio of 1.742 , with a significance level of 0.1792 , indicates that the groups did not differ significantly. This means that the simplified text did not make a significant difference. Clearly, further research is necessary in this area. It may mean that the changes are not farreaching enough, that a different set of principles should be used in simplifying the text, or that the level of the students' English was such that access to a simplified text made little difference. It may well be that the fact that the teaching was in English and the questionnaire was also in English had a levelling effect.

\subsection{The Test on Elements and Compounds}

Before answering the questionnaire, students were divided into three groups. Each of the groups was taught by the same teacher (one of the project leaders). The elimination of one possible variable was making the effect of greater language support emerge more clearly. The intervention took the form of making the 'textbook' as comprehensible as possible. The first group (8A) received a simplified version of the chapter in the textbook as well as an extended summary in English. The second group (8B) used the unadapted text of the textbook and were given the same extended summary in English that the first group had been given. The third group, like the second group, used the unadapted text of the textbook, but unlike the other two groups, the extended summary with which they were provided, was in isiXhosa, the home language of all of the students. Unfortunately, at least two factors made it difficult to draw clear conclusions. One is the size of the groups. Group A had 37 students, group B had 52 students and group $\mathrm{C}$ had 44 students. The other factor relates to the support material. Fifteen of the students in group $\mathrm{C}$ admitted that they did not use the extended summary. It is a fair assumption that some of the others were reluctant to the admit that they had not done so, in which case the number who actually did not use the summary would be greater than this. In any case, the number of those who did use isiXhosa (29 at best) is too small to make reliable comparisons with the other 104 students possible. As the researchers themselves conclude, those who did choose to use the summary were probably more highly motivated. This reduces the validity of comparisons between those who had the support of an isiXhosa text and those who did not.

The reasons for not using the isiXhosa summary were not explored. It would seem to present an interesting area of research. Several factors could have come into play. Less motivated students are likely to 'do the minimum', for example. Another factor could be a perception that isiXhosa is a less effective tool of learning than English or that the content in the textbook would be more reliable.

Two types of questions were used to elicit answers in the test: true and false and multiple choice. To reduce the element of guessing, students were asked to give a reason if they chose the false option. However, avoiding having to give a reason was such a strong consideration that students tended to select the true option. Confirmation of this is to be seen in the fact that $81,2 \%, 74.4 \%, 69.9 \%, 76.7 \%, 75.2 \%, 72.9 \%$ and $73.7 \%$ respectively chose the true option for questions $1,2,6,7,8,12$ and 13 , while the answers were actually false. 


\section{RECOMMENDATIONS AND CONCLUSIONS}

While it is important to take note of the gaps in the knowledge students appear to have, the comments in this section will be confined to matters relating to language. There seems good reason to believe that a higher level of proficiency in language will result in an improvement in vocabulary knowledge as well as the general language skills.

There is strong support in the literature for mother-tongue instruction (e.g. Bambose 1984; Barba 1993; Collison 1974; Fishman 1984; Nangu in Glencross 1994) in the early years so that a firm foundation can be provided for further education. The deleterious effects of a transition from mother tongue to English as a medium after only four years of inadequate schooling have been well documented in southern Africa (see Macdonald 1990). Furthermore, it is necessary to ensure that the students have acquired the necessary strategic tools in English before the transition is made. This is affirmed by Macdonald and Burroughs (1991:25):

... the curriculum should be structured in such a way as to help the learners achieve a sufficient level of fluency, confidence and vocabulary to enable them to cope when they are presented with more demanding and abstract school subjects in the medium of English.

Students also need a high level of skill in reading. As Macdonald and Burroughs (1991) point out, reading textbooks in a second language is more complex because the reader has to deal with new vocabulary and new grammar in trying to understand and process new ideas. A subject like chemistry places particular demands on the interweaving of thought and language which underpins the meaning-making process and thus increases the problem. In many respects chemistry as a subject is abstract which often requires formal operational reasoning (Ben-Zvi et al. 1988:89-92, Herron 1975:146-150). If students experience problems in understanding even words in common use or basic scientific terms, they will have very little chance of making sense of the chemistry they have to learn.

By extension, the findings in this study lend support to the view presented by Macdonald and Burroughs (1991). Their research led them to believe that standard 3 students had not mastered the skill of reading fluently even texts that contained stories and information they already knew. This led them to the conclusion that these students had not reached the stage when they could start reading to learn (Macdonald and Burroughs 1991:47, 51). This study suggests that the handicap is not overcome: students do not appear to have the language skills to allow them to read-to-learn.

There are no easy solutions to the problem. A present reality is that the majority of black high school students are taught through the medium of English. Attempts to change this situation are unlikely to meet with success in the short term. ${ }^{2}$ The lack of materials in black languages and the powerful attraction of an international language are only two of the reasons that explain the strong support by parents for education through the medium of English. There seems little doubt that English is emerging as the lingua franca of urban life and consequently 
of business, political life and the academic world and the public media, and that it will continue to develop in this role.

Whatever the long-term situation, a number of measures can be taken immediately to reduce the problems which black students appear to experience:

\subsection{Bilingual education}

Some studies (e.g. Meyer 1995) have produced evidence to show that English only is the exception rather than the rule. What is required is an acknowledgement of the de facto situation which is that neither the students or the teachers in the majority of schools are capable of using English at a sufficiently high level. One solution is to adopt a mixed language approach (dual medium) (Rollnick and Rutherford (1993:378). Ideally, small group discussion should proceed in the mother tongue (in this case, isiXhosa) and students ${ }^{3}$ should be encouraged to ask questions in the mother tongue. The transition from isiXhosa to English should be made gradually, so that students are not required to operate beyond their level of competence. There should be a readiness to provide explanations in isiXhosa at any stage in the interests of a high level of comprehension. At present it appears that the students in this survey seem only partially to understand what is explained in class. In an English only environment, their poor command of English and their lack of confidence are likely to discourage them from asking questions.

\section{2 'Borrowing' of terms}

English is only one of the languages that has drawn extensively on the strategy of borrowing terms from other languages. It would be ludicrous to argue that this has weakened English as a language. In the case of black languages which lack scientific terms, there are obvious academic advantages in extending vocabulary by borrowing from an international language. It should, in fact, strengthen the case for more extensive use of isiXhosa.

\subsection{High level of active participation}

Lessons should make generous provision for discussion, for questions to be asked and for students to be engaged in doing experiments for themselves. In this way, language development and the development of a greater understanding would be fostered.

\subsection{Need for English as a subject to be strengthened and redefined}

The policy documents and the information on the language, literacy and communication curriculum are short on attention to the development of skills relating to the use of language as a tool. The desired outcome of English teaching (as part of the Language, Literacy and Communication area) must be proficient, and there must be an accurate use of English as an effective tool to make the acquisition of concepts in science, for instance, possible. In this context English cannot function merely as an additional language - it has to serve as a main language (i.e. a language that can be used to learn efficiently and effectively). As is evident 
even from the superficial analysis of the findings of the Jordaan and Nangu (1986) study, the inability to use and understand English scientific discourse accurately hampers learning. The ability, therefore, to 'communicate' (where this is equated with the ability to operate at a minimal level) may serve certain social needs but is quite simply inadequate for the students who have do some of their learning through English. Here accuracy is used in the sense of precise meaning which is accorded to certain words and terms within a scientific context.

\subsection{The development of a familiarity with scientific discourse}

The list compiled by Jordaan and Nangu (1996) is a useful one in its own right, but it has much greater importance as a means of highlighting the complex difficulties students face. It alerts teachers to the need to ensure that terms and general vocabulary used are understood. This includes close attention to careful articulation so that confusion between words is not created.

Language should not be a barrier to the acquisition of concepts and scientific knowledge. Wherever possible unfamiliar terms or vocabulary or those known to present problems should be glossed or illustrated. Practice should take account of the fact that internalisation is often a slow process: teachers should do all they can to enable students to consolidate their learning. It is vital that opportunities be created for students to express and exchange personal interpretations of core concepts.

Gee (1990) and Russell (1991) are among those who have demonstrated the ways in which particular discourses can act as gatekeepers. The rather 'confused' utterances which respondents gave in this study could be described as hybridisation (Recchio 1991), which result from the inability to identify and manage interacting discourses. According to Gee (1990), management of discourses requires an acquisition and a learning process. Acquisition results from interaction in a supportive environment with those who have mastered the discourse and leads to improved performance. Learning, on the other hand, leads to better meta-level knowledge, which enhances insight and understanding of the features that distinguish particular discourses. This contributes to enhanced performance. What learners need is the opportunity to serve as apprentices so they can move to a position of 'mastery'. They need the skills to develop increasingly refined understandings of core concepts within the context of particular uses of language.

\section{REFERENCES}

BAMGBOSE, A. 1984. Mother tongue medium and scholastic attainment in Nigeria. Prospects, 24(1).

BARBA, RH. 1993. A study of culturally syntonic variables in the bilingual/bicultural science classroom. Journal of Research in Science Teaching, 30(9).

BEN-ZVI, R, B EYLON AND J SILVERSTEIN. 1988. Theories, principles and laws. Education in Chemistry, 25 (1). 
CASSELS, JRT AND AH JOHNSTONE. 1983. The meaning of words and the teaching of chemistry. Education in Chemistry, 20(1):10-11.

CASSELS, JRT AND AH JOHNSTONE. 1985. Words that matter in science: A Report of a Research Exercise. London: Royal Society of Chemistry.

COLLISON, GO. 1974. Concept formation in a second language: a study of Ghanaian children. Harvard Educational Review, 44(3).

FARRAR, M. 1994. Teaching chemistry to students for whom English is a second language. In R Levinson (ed.) Teaching Science. London: Routledge.

FISHMAN, JA. 1984. Minority languages in education. Prospects, 24(1).

GEE, J. 1990. Social linguistics and literacies: Ideology in discourses. Basingstoke: Falmer Press.

JORDAAN, AS AND NC NANGU. 1996. The influence of written text on std 6 students' understanding of elements and compounds. A research report submitted to the Foundation for Research Development.

MACDONALD, CA. 1990. Crossing the threshold into Standard Three: The main consolidated report. Pretoria: HSRC.

MACDONALD, C AND E BURROUGHS. 1991. Eager to talk and to learn and think. Cape Town: Maskew Miller Longman.

MEYER, D. 1985. What is the actual medium of instruction in formerly black secondary schools? Current practice and its implications for language policy formulation. Per Linguam, 11(2).

NANGU, NC. 1994. How can we be expected to learn in science. In Glencross, MJ (ed). Proceedings of the second annual meeting of the Southern African Association for Research in Mathematics and Science Education, University of DurbanWestville, Westville.

RECCHIO, T. 1991. A Baktinian reading of student writing. College Composition and Communication, 42(6):446-454.

ROLLNICK, M AND M RUTHERFORD. 1993. The use of a conceptual change model and mixed language strategy for remediating misconceptions on air pressure.

International Journal of Science Eduction of 15(4): 101-103.

RUSSELL, D. 1990. Writing across the curriculum in the historical perspective: Towards a social interpretation. College English 52(1):52-73. 